\title{
The role of scientific research on nuclear radiation waste management and preserving environment
} \author{
and Chakir Elmahjoub ${ }^{1}$ \\ ${ }^{1}$ Materials and Subatomic Physics Laboratory- LPMS, Ibn Tofail University- Kenitra,Morocco \\ ${ }^{2}$ University of Poitiers, France \\ ${ }^{3}$ Mohammed V University - ENSEM RABAT \\ ${ }^{4}$ Abdemalek Saadi University, Science Faculty - ERSN
}

Abdulsamad Alhousali ${ }^{1, *}$, Salmane Bourekkadi ${ }^{2}$, Mohamed Azougagh ${ }^{3}$, Hamid Boukhal ${ }^{4}$, Elmehdi Alibrahimi $^{1}$,

\begin{abstract}
On the level of this article, we deal with nuclear radiation (and their residues), which is defined as a physical phenomenon and strong atomic activity that occurs in unstable atoms of elements. We are interested in studying radiation as the emission or diffusion of energy into space in the form of electromagnetic waves or particles. The scientist Fermi (1934 AD) is among the first to present scientific research in this field. Radioisotopes are considered one of the most prominent discoveries of modern science and based on the importance of the topic, scientists and researchers searched for methods and techniques to facilitate the implementation of practical applications for radiation measurement, and among those methods a specialized program was used to simulate radiation dose (digital simulation in a computer through the use of an imaginary model of the radiometric process with technology Monte Carlo using code (Geant 4). We have also highlighted the views of researchers and specialists in the area of disposal of radioactive waste, relying on a field study and a comparison of some of the currently adopted techniques to get rid of the negative consequences that each unreasonable (reckless) management and measure of this radioactive waste may have Among the most prominent results we have reached is highlighting the weakness of dealing with this topic and not giving it the right to research and scientific achievements carried out by researchers, which increases the complexity of the situation and from which it is difficult to control the problem in the future.
\end{abstract}

\section{Introduction}

At the beginning of the last century, the so-called term nuclear radiation began to appear, after some research scientists conducted a set of experiments to obtain isotopes of elements by bombarding nuclei with neutrons, which produced the element uranium, which has an unstable nucleus. The experiment of the scientist (Fermi) in $1934 \mathrm{AD}$ was the way to discover the element uranium, who expected that bombarding the element with neutrons would lead to an unstable nucleus that releases beta particles, which may lead to an increase in the atomic number from 92 to 93 and the production of a new element in the periodic table, but he was unable to know the results $[3,4]$.

At the beginning of the last century, the so-called term nuclear radiation And research continued until the German scientist (Nodak) was able to identify the products of the reaction (the uranium nucleus is split into two medium-mass nuclei), which is expressed by nuclear fission, which studies have confirmed with the passage of time, and this fission produces huge amounts of energy as a result of the nuclear reaction $[7,8]$.
Fission occurs by bombarding the heavy uranium nucleus (235 in mass number 92 in atomic number) with neutrons, which are relatively light particles, and are considered the best shells because they do not carry a charge [6].

It should be noted that exposure to these radiation has side effects that cause chemical changes in the tissues of living organisms according to the amount of radiation dose that the body was exposed to, and symptoms may not appear quickly on the person who was exposed to these radiations, as the radiation may be in the latency stage (the incubation period for radiation), The type of injury that results from these radiations may be identified by determining the source and type of these radiation, and a study of the results of the nuclear explosions that occurred during World War II in the Japanese city of Hiroshima showed the extent of the danger of nuclear radiation, which may cause the emergence of many diseases and health risks resulting from exposure to those nuclear radiation, in addition to doing a set of experiments on animals, and through the following table we learn about some diseases and risks resulting from human exposure to these nuclear radiation[1,2,5]:

\footnotetext{
Corresponding author: alhousali.abdulsamadmohammedabdo@uit.ac.ma
} 
Table 1.Some diseases and risks resulting from human exposure to these nuclear radiation

\begin{tabular}{|c|l|}
\hline The disease & Illustration \\
\hline cancer & $\begin{array}{l}\text { The emergence of various } \\
\text { cancerous diseases } \\
\text { according to the amount of } \\
\text { radiation dose and the area of } \\
\text { injury, especially when } \\
\text { exposed to a high amount of } \\
\text { radiation. }\end{array}$ \\
\hline Cataract of the eye lens & $\begin{array}{l}\text { Exposure to radiation during } \\
\text { vision may cause permanent } \\
\text { damage to the lens of the eye, } \\
\text { which may lead to vision loss }\end{array}$ \\
\hline \multirow{3}{*}{ infertility } & $\begin{array}{l}\text { Permanent exposure to the } \\
\text { human genitals may impair } \\
\text { fertility, which in turn may lead } \\
\text { to infertility }\end{array}$ \\
\hline
\end{tabular}

Exposure to high radiation doses for long periods of time may lead to a deterioration in the body's immunity, which may be a cause of death $[9,10]$.

Notice:

It should be noted that nuclear radiation is used to alleviate cancer by breaking up carcinogenic masses, even though cancer is one of the resulting diseases.

\section{Main research methods}

After presenting the general framework that best fits our study, these are the most important stages:

First, a presentation of the used methodology. After that, the data collection tools are presented to know the applied methods for processing the questionnaire.

\subsection{Research Methodology}

In a survey, the questionnaire remains the primary tool of gathering primary data. The questionnaire is used to obtain any initial data from researchers on their opinions, attitudes and activities on the topic. This questionnaire is to study the issue of radioactive waste management and ways to develop it, exchange experiences, opinions and consultations, including discussion of recent developments while improving safety standards when storing or disposing of radioactive waste.

The questions we have chosen are transparent to varying degrees so that the respondents know the purpose of the research, and the questions asked will be closed - direct, open - direct, open - indirect, closed - indirect. We have questions regarding all aspects of the research.

\subsection{The approach followed in this study}

Free, inexpensive and advanced modern technology tools have been used, and these tools are characterized by the fact that they help us quickly communicate with researchers specialized in this field.

After completing the preparation of this questionnaire, we shared it with a group of researchers and specialists in the field of nuclear radiation management and ways to develop it by using a range of technologies such as e-mail, Facebook groups, WhatsApp, and other social media.

Table 2. The types of questions.

\begin{tabular}{|c|c|}
\hline \multicolumn{2}{|r|}{ Questions } \\
\hline $\begin{array}{l}\text { Closed - direct } \\
\text { questionnaire }\end{array}$ & $\begin{array}{l}\text { The direct closed questionnaire is the } \\
\text { most common, the possible questions } \\
\text { and answers are predetermined, and } \\
\text { the purpose of the study is clear to the } \\
\text { participant from the start. } \\
\text { This questionnaire has been } \\
\text { constructed in such a way that it } \\
\text { allows easy counting and good } \\
\text { interpretation of the answers. } \\
\text { There are two types of questions: } \\
\text { dichotomous and multiple choice } \\
\text { questions. A dichotomous question } \\
\text { leaves the respondent only the choice } \\
\text { between two possible answers. } \\
\text { Multiple choice questions are also } \\
\text { known and allow the participant to } \\
\text { choose the best among several } \\
\text { answers. However, none of the } \\
\text { answers may be entirely appropriate } \\
\text { and the participant may wish to have } \\
\text { other options. A closed questionnaire } \\
\text { is most effective when potential } \\
\text { answers are clearly identified, well } \\
\text { understood, and few in number. }\end{array}$ \\
\hline $\begin{array}{l}\text { Open - direct } \\
\text { Questionnaire }\end{array}$ & $\begin{array}{l}\text { In a direct open questionnaire, the } \\
\text { wording of the questions differs: they are } \\
\text { usually open-ended. The interviewer will } \\
\text { not ask any dichotomous questions or } \\
\text { multiple choice questions, and he } \\
\text { probably will not have a pre-defined list } \\
\text { of questions because he wants to allow } \\
\text { the participant to speak as freely as } \\
\text { possible, instead of asking }\end{array}$ \\
\hline $\begin{array}{l}\text { Open - indirect } \\
\text { questionnaire }\end{array}$ & $\begin{array}{l}\text { The main advantage of this } \\
\text { questionnaire is undoubtedly the } \\
\text { possibility to collect data that the } \\
\text { participant can or cannot provide } \\
\text { through a direct or closed approach }\end{array}$ \\
\hline $\begin{array}{l}\text { Closed-indirect } \\
\text { questionnaire }\end{array}$ & $\begin{array}{l}\text { It also aims to hide the truth from the } \\
\text { participant, but it is under study. The } \\
\text { main advantage of the indirect survey } \\
\text { for closed evaluators is the ease of } \\
\text { completing and interpreting the } \\
\text { results }\end{array}$ \\
\hline
\end{tabular}

We have also relied on direct interviews and conversations through the use of remote social media platforms.

It should also be noted that the collection of this data came at a critical period as a result of the complete closure and the inability to communicate directly and move to collect data due to the spread of the Covid 19 epidemic at such a time, and the tools of modern technology used in remote communication allow us the opportunity to complete this study and collect Data despite all circumstances.

After collecting data and proceeding to analyze them and draw conclusions from them, it was found that their 
geographical distribution is important, as it included six countries distributed on four continents, namely Yemen Morocco - France - Egypt - Algeria - Turkey - the United States of America (this arrangement was based on the proportion of participants from largest to smallest).

The ages of the participants included all groups over 20 years old, as the ages from 30 to 40 years participated by more than $80 \%$, and ages between 20 and 30 years, participated by $10 \%$, and the same percentage was for the age group of 40 years and over.

It should also be noted that the percentage of participating doctors was the highest compared to $\mathrm{PhD}$ researchers, with three quarters of the participants.

\begin{tabular}{|c|}
\hline Information Analysis \\
\hline Specifying the general goals \\
\hline Determine stimulating strategies to achieve these goals \\
Determine actions to help develop radioactive waste \\
management
\end{tabular}

\section{a) The aim of this research (questionnaire)}

Table 3. The main objective and Specific goals.

\begin{tabular}{|l|l|l|}
\hline \multicolumn{3}{|c|}{ The main objective } \\
\hline \multicolumn{2}{|c|}{ Study ways to develop radioactive waste management } \\
\hline $\begin{array}{l}\text { Promote reporting } \\
\text { and formalization } \\
\text { of information on } \\
\text { developing } \\
\text { radioactive waste } \\
\text { management }\end{array}$ & $\begin{array}{l}\text { Seize } \\
\text { opportunities and } \\
\text { resources to } \\
\text { protect humans } \\
\text { and the } \\
\text { environment from } \\
\text { leakage of these } \\
\text { radiations }\end{array}$ & $\begin{array}{l}\text { Listening to the } \\
\text { opinions of } \\
\text { researchers in } \\
\text { order to reach } \\
\text { results that } \\
\text { contribute to } \\
\text { creating a clean } \\
\text { environment free } \\
\text { of radiation }\end{array}$ \\
\hline
\end{tabular}

\section{b) Field of Study}

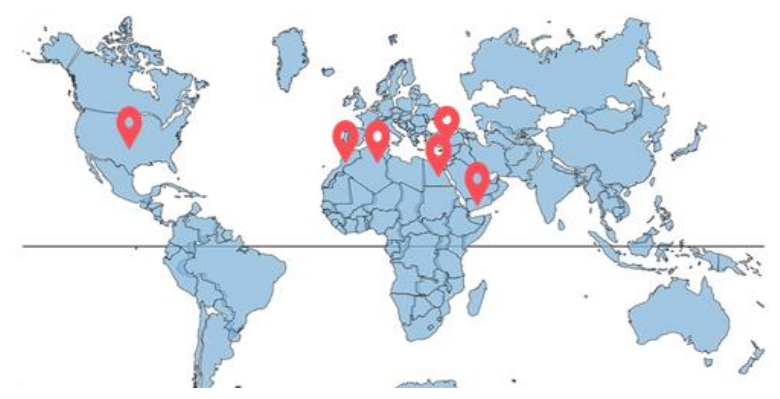

Fig.1. Geographical distribution of the field of research.

\section{Data collection}

In our time and in light of the rapid advancement of modern technology and various technologies, nuclear energy (nuclear radiation) has become one of the important means of producing energy used in various fields related to our daily life. However, nuclear energy has grave effects, as the radiation emitted from it has negative effects, whether on human health or the surrounding environment, and studying the management of these radiations' waste and ways to develop them has become an essential need due to its impact on the environment surrounding humans, which may endanger many lives, including human health.

Given the importance of studying this field, we created this questionnaire, which aims to study the role of developing scientific research in the field of nuclear radiation waste and its impact on preserving the environment .

This questionnaire consists of 18 different questions between determining the target's gender, age, country to which he belongs, the degree he attained, the number of conferences and seminars that have been participated in, the importance of research and development in the field of nuclear radiation, and the number of scientific articles that have been published by the researchers targeted in the questionnaire, and the programming languages and technology tools that have been relied on in their research, estimating the percentage worthy of scientific research aimed at preserving the environment and the Earth, and the sources of radioactive waste that have been addressed in such research, and trying to predict the percentage of risk that this radioactive waste causes to the environment, and the extent to which states fulfill their duty to preserve the environment from the repercussions of these radioactive wastes, and to estimate the harmful effects on doctors and workers in this field when using these radiations in the medical field.

The questionnaire also aims to measure the extent of the researcher's and developer's satisfaction in this field regarding the number of scientific conferences or seminars that are organized to exchange experiences, opinions and consultations on this topic, and to discuss recent developments while improving safety standards when storing or disposing of radioactive waste.

We also tried to take the opinion of those targeted in this questionnaire about some countries launching an initiative to end the use of nuclear energy (radiological) in order to avoid any environmental disasters such as the disaster of the Tchir Nobel nuclear reactor explosion in Ukraine in 1986, in addition to concerns about how to get rid of radioactive waste.

The following is a list of questions as mentioned in the questionnaire:

- Degree

- The number of conferences or seminars you have participated in

- Do you think this topic is worth discussing?

- How many scientific articles or publications have you published?

- If so, what are the programming languages and technology tools that you relied on in your research?

- From your perspective, what percentage is worthy of scientific research aimed at preserving the environment and the planet?

- What is the percentage of effective storage options and methods used to reduce the leakage of such radioactive wastes? 
- What are the sources of radioactive waste that you covered in your research?

- What is the percentage of risk that this radioactive waste causes to the environment?

- Are countries fulfilling their duty to preserve the environment from the repercussions of this radioactive waste?

- Through the use of radiation in the medical field, do you see that it has harmful effects on doctors and workers in this field despite the tools of prevention?

- Are you satisfied with the number of scientific conferences or seminars that are organized to exchange experiences, opinions and consultations on this topic, and to discuss recent developments while improving safety standards when storing or disposing of radioactive waste?

- Do you support the launching of an initiative by some countries to end the use of nuclear energy (radiological) in order to avoid any environmental disasters such as the disaster of the explosion of the Nobel nuclear reactor in Ukraine in $1986 \mathrm{AD}$, in addition to the concern about how to get rid of radioactive waste?

- If you could kindly see that there are important scientific articles on this topic, would you please share the links to these articles?

- Please do you have any suggestions about ways to develop the field of radioactive waste management?

\subsection{Data collection and analysis techniques}

These questions that were asked in this questionnaire were approved by researchers specializing in this field, and when doing this questionnaire we tried to replace it from a printed paper to a digital questionnaire in order to save time, effort and money, and we are keen to reach the farthest places, and modern technology has been used free, inexpensive but advanced at the same time, these tools are characterized by the fact that they help us quickly communicate with researchers specialized in this field.

After completing the preparation of this questionnaire, we shared it with a group of researchers and specialists in the field of nuclear radiation management and ways to develop it by using a range of technologies such as e-mail, Facebook groups, WhatsApp, and other social media.

We have also relied on direct interviews and conversations through the use of remote social media platforms. It should also be noted that data collection came at a critical period as a result of the complete closure and the inability to communicate directly and move to collect data due to the spread of the Covid 19 epidemic at such a time, and the modern technology used in remote communication gives us the opportunity to complete this study and collect data despite all the circumstances.

\section{Data analysis}

After collecting data and proceeding to analyze them and draw conclusions from them, it was found that their geographical distribution is important [6], as it included six countries distributed on four continents, namely Yemen - Morocco - France - Egypt - Algeria - Turkey and the United States of America (this arrangement was based on the proportion of participants from largest to smallest ).

The ages of the participants included all groups over 20 years old, as the ages from 30 to 40 years participated by more than $80 \%$, and ages between 20 and 30 years, participated by $10 \%$, and the same percentage was for the age group of 40 years and over.

It should also be noted that the percentage of participating doctors was the highest compared to researchers in the $\mathrm{PhD}$, with three quarters of the participants

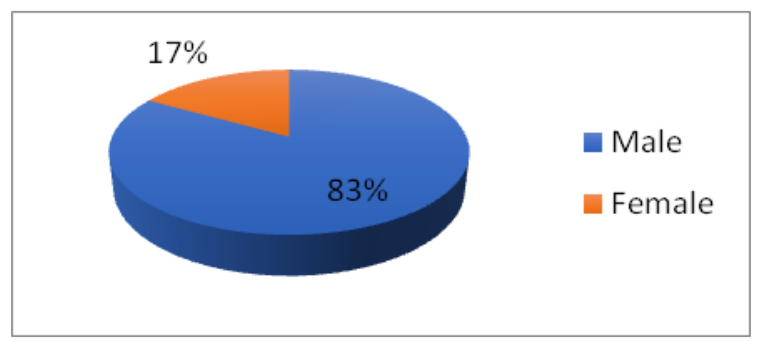

Fig.2. Percentage of male and female respondents.

The above figure No.(2), shows the percentage of males and females participating in this questionnaire, the percentage of males is $83.3 \%$, while the percentage of females is $16.7 \%$.

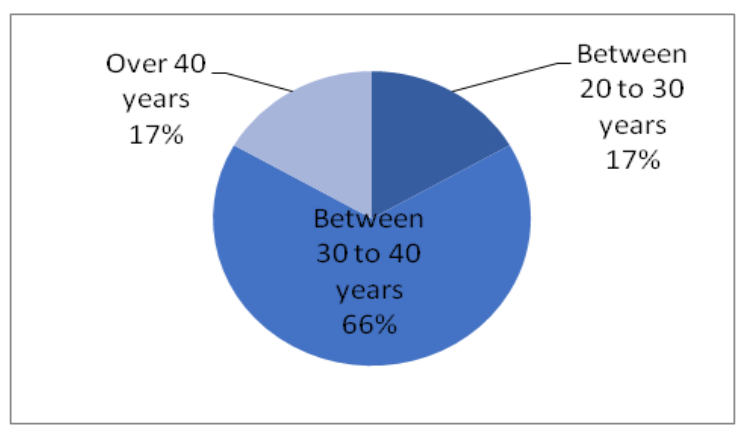

Fig.3.Ages of survey participants.

The above figure No.(3), shows the age group of the participants in this questionnaire, $66.7 \%$ is the percentage of participants between 30 and 40 years, the participants between 20 to 30 years with a percentage of $16.7 \%$, and the participants over 40 years of age with a percentage of $16.7 \%$.

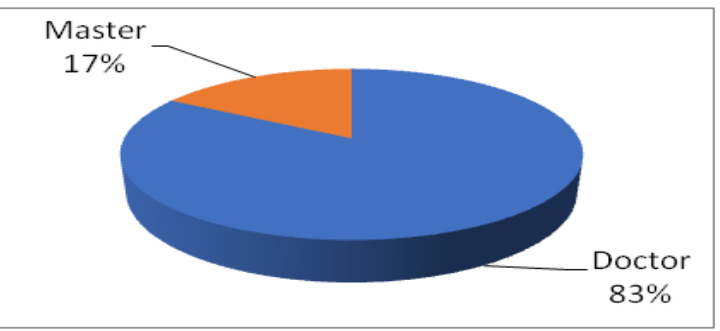

Fig.4. Degree of survey respondents. 
The figure above No. (4) shows the academic degree of the participants in this questionnaire, Ph.D. (83.3\%), and researchers in the $\mathrm{PhD}(16.7 \%)$.

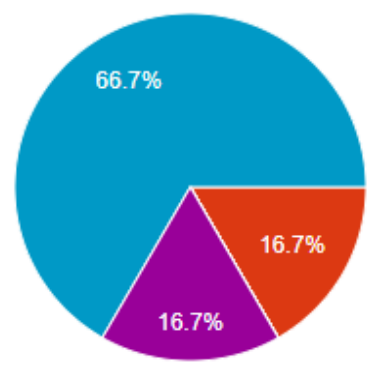

Fig.5.Number of conferences and seminars for participants.

The figure above (5) shows the number of conferences and seminars for the participants in the questionnaire, who participated in more than 10 (66.7\%), more than 5 and less than $10(16.7 \%)$, less than 5 by $(16.7 \%)$.

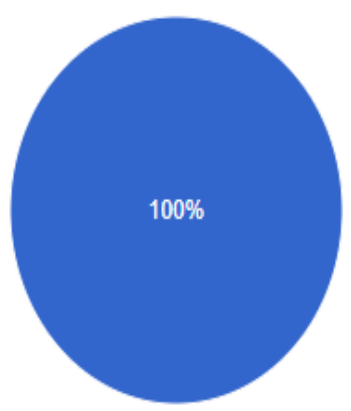

Fig.6. Importance of researching the topic of the questionnaire.

Figure No.(6), examines the researchers 'opinion regarding the merit of the subject for research. The answer was yes by $(100 \%)$, and the rest of the options $(0 \%)$.

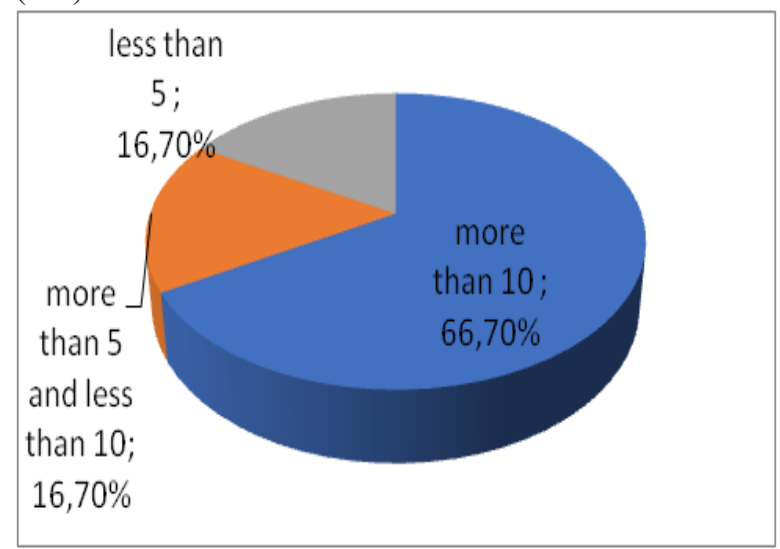

Fig.7.Number of survey respondents' scientific articles.

Figure No.(7), shows the number of scientific articles for the participants in the questionnaire, more than 10 scientific articles at a rate of $(66.7 \%)$, more than 5 and less than 10 scientific articles at a rate of $(16.7 \%)$, and less than 5 scientific articles at a rate of $(16.7 \%)$.

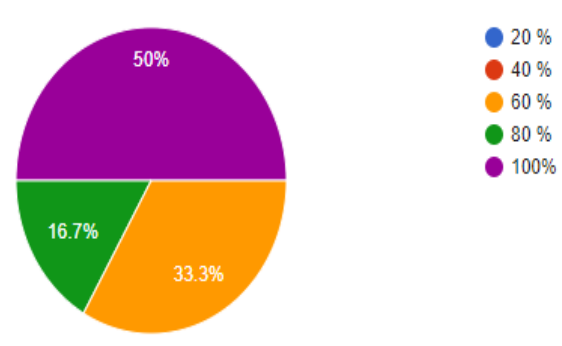

Fig.8.Percentage worthy of scientific research aimed at preserving the environment and the planet.

Figure No.(8), expresses the percentage worthy of scientific research aimed at preserving the environment and the globe. $(50 \%)$ of the respondents believed that research on this topic deserves a percentage (100\%), while we note that the percentage $(33.3 \%)$ Of the respondents believe that scientific research in this field is worth only $(60 \%)$, and the rest $(16.7 \%)$ believes that scientific research in this field is worth $(80 \%)$.

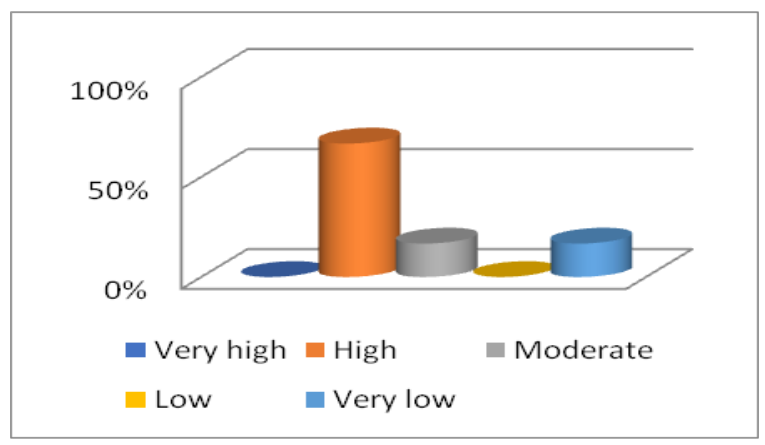

Fig.9.The effectiveness of storage options and methodsused to reduce the leakage of such radioactive waste.

From Figure No.(9), it is clear that (16.7\%) of the respondents saw that the effectiveness of storage options and the methods used to limit the leakage of such radioactive waste is high, while $(66.7 \%)$ saw that it is moderate, and the rest of the respondents noted By $(16.7 \%)$ it is very low.

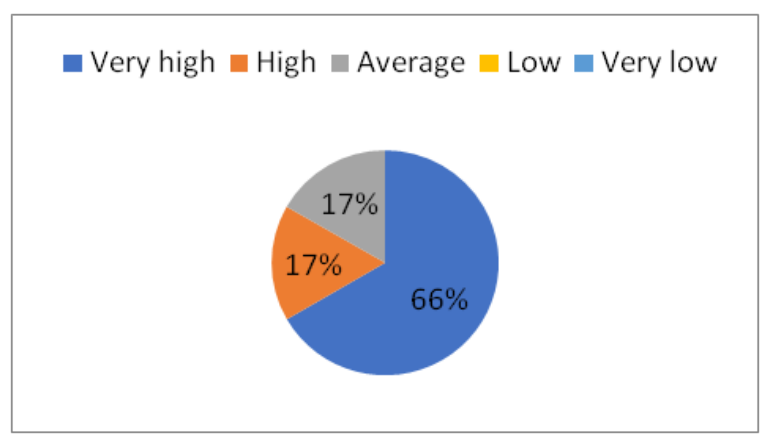

Fig.10.is the environmental risk this radioactive waste has.

Figure No.(10), shows that $(66.7 \%)$ of the respondents saw the percentage of risk that this radioactive waste causes to the environment to be very high, while $(16.7 \%)$ saw that it is high, and the rest of the respondents noticed $(16.7 \%)$ It is average. 


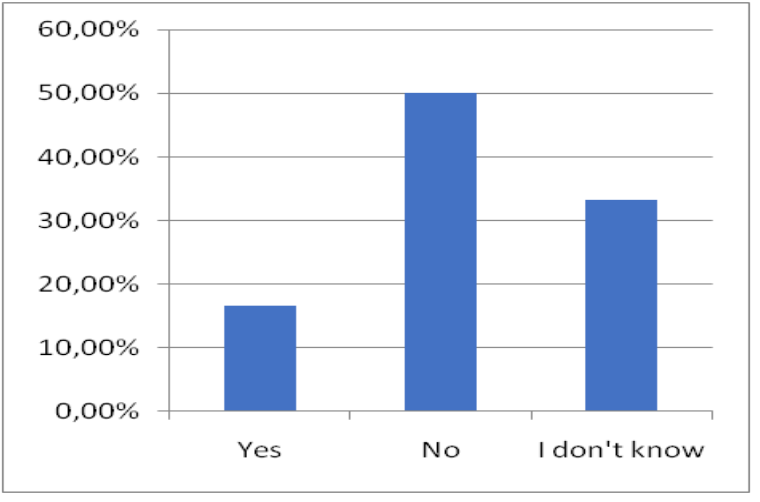

Fig.11.Countries fulfilling their duty to protect the environment from the impacts of this radioactive waste.

Through Figure No.(11), (16.7\%) of the respondents answered yes to the extent of countries fulfilling their duty to preserve the environment from the reflections of these radioactive waste, while $(50 \%)$ of the respondents saw the choice no, and the rest by $(33.3 \%)$ They answered, "I don't know."

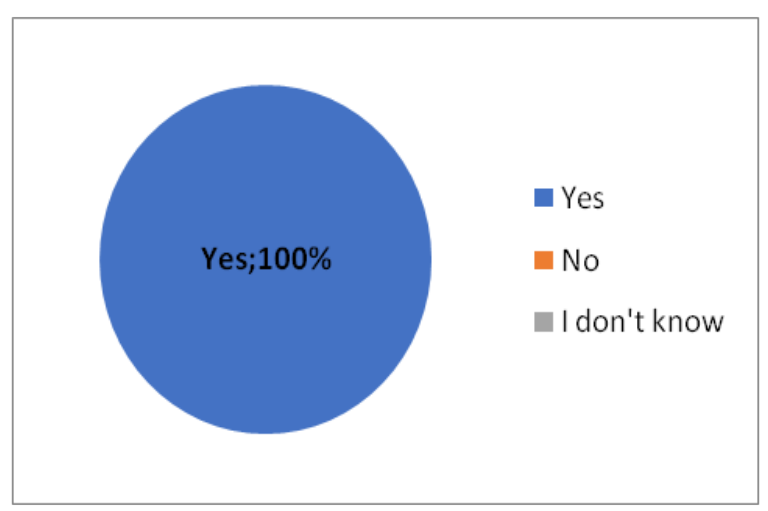

Fig.12.Harmful effects on doctors and workers in this field despite prevention.

Through Figure No.(12), we notice that $100 \%$ of those targeted in this questionnaire answered yes to the extent of the harmful effects of such radiation.

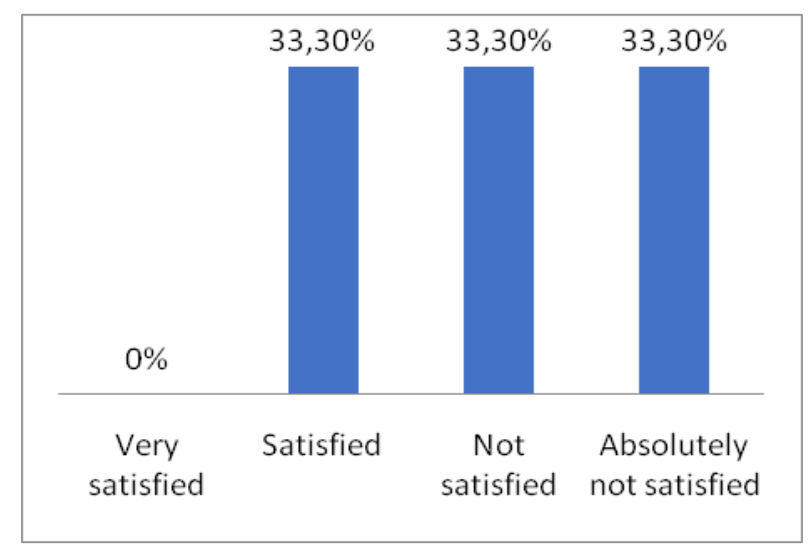

Fig.13.Satisfaction with the number of scientific conferences or seminars on radioactive waste management.

Through Figure No.(13), (33.3\%) of those targeted in this questionnaire answered satisfied with the question set about the extent of satisfaction with the number of scientific conferences or seminars that are organized to exchange experiences and discuss recent developments while improving safety standards when storing or disposing Radioactive waste, while $(33,3 \%)$ of the respondents saw the choice as dissatisfied, and the rest $(33,3 \%)$ answered with no satisfaction at all.

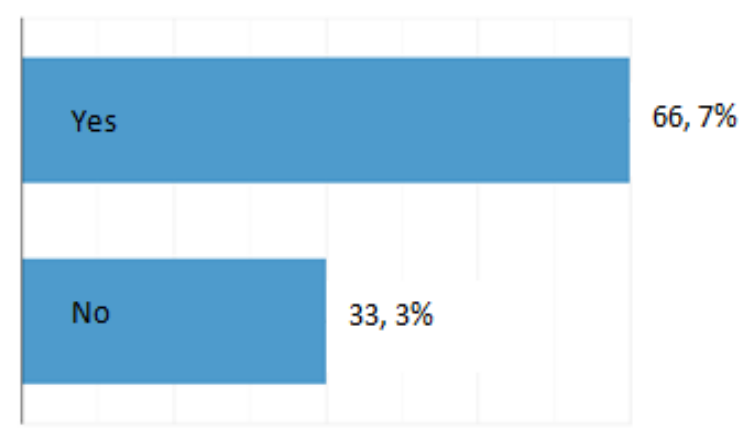

Fig.14.Support for some countries to launch an initiative to end the use of nuclear (radiological) energy.

Figure No.(14), shows the percentage of support for some countries to launch the initiative to end the use of nuclear energy (radiological). We note that $(66.7 \%)$ agree on the answer with yes, while the rest of $(33.3 \%)$ answered no.

\section{Results}

One of the most important findings of this research is that the percentage of female researchers in this field is less compared to male researchers due to the difficult conditions required by research in this field. It should also be noted that the young age group is the most involved in scientific research in The field of nuclear radiation waste management, especially for holders of higher degrees.

The participants who hold a $\mathrm{PhD}$ exceeded $80 \%$ and were distributed over a group of countries. They also have accumulated experience as a result of their scientific activity, as they have participated in many scientific conferences at a rate of more than 10 conferences specialized in nuclear radiation management. This indicates that the data that we have collected has credibility and scientific value and also carries recommendations that must be dealt with professionally. These results can open up other areas and horizons for us to search and delve into everything that would protect the Earth and its people from all creatures.

These are the most important points that this research concluded:

- The need for continuity in scientific production in the field of radioactive waste management

-The necessity of sharing new data in the field of nuclear radiation management

-The lack of proportion between the average number of scientific papers completed and the academic qualifications of the participants in the questionnaire. See figure $\mathrm{No}($ )

- The diversity of programming languages used by the researchers in this questionnaire 
(Linux, Excel, MATLAB, castam, Nemrodw, Zotero, Fortran, C ++ , Python, MONTE CARLO SIMULATION.)

- The need for all disciplines (law - economics computer science - human sciences ...) to be open to issues that aim to contribute to preserving the environment, land and energy.

- The need to adopt safer and more secure storage options for human health and the surrounding environment, taking into account the methods used to limit the leakage of such radioactive waste.

- The necessity to find effective solutions to deal with the most active sources of radioactive waste (radioisotopes in scientific research, industry, mining and agriculture - nuclear medicine, including diagnosis, treatment, and drug production ...)

- The failure of some countries to deal with radioactive waste in an early period.

- Emphasizing the need to adhere to the necessary precautions when disposing of radioactive waste in the medical field.

- A severe shortage of scientific activities that are concerned with the field of radioactive waste management and ways to develop them.

- Continuing to support the initiative to end the use of nuclear energy (radiological) in order to avoid any environmental disasters such as the disaster of the explosion of the Cher Noble nuclear reactor in Ukraine in 1986, in addition to concerns about how to dispose of radioactive waste.

\section{Discussion}

Through this research, we tried to reach the largest possible number of countries that are concerned with studying the field of nuclear radiation and how to get rid of radioactive waste, and to establish partnerships with heads of laboratories active in this field, and we made efforts to travel to obtain information in the field, but due to the outbreak of the Covid 19 epidemic, it could not be achieved.

This research was the result of a continuous study of the subject of nuclear radiation and how to manage radioactive waste. It was noted that communication is not sufficient and given the importance of the topic in preserving the human being and the environment around him. Based on that, we hope that a permanent control system will be created over countries that exploit nuclear radiation in their various activities. In addition to holding more conferences and seminars for specialists in this field from various countries in order to exchange views and experiences in the hope of reaching a safe and clean environment from the remnants of these nuclear radiation.

\section{Conclusion}

Through this research, we tried to communicate with a group of researchers and specialists in the field of radioactive waste management to benefit from their experiences and try to reach more effective results to contribute to expanding the research circle by highlighting the different aspects and the various methods that researchers take to develop this field, and what distinguishes this is to shed light on the important role that researchers play in harnessing their energies to develop the methods used to reduce the negative effects that result from the spread of radioactive waste, based on their human role in preserving human health and the surrounding environment.

\section{Future Work}

In future work, we will try to work on these results and shed light on the methods and techniques used to facilitate the practical applications of radiation measurement, and we will also make applications on one of the methods, most notably through the use of a specialized program to simulate radiation dose (digital simulation in the computer through the use of an imaginary model of the radiometric process Monte Carlo technique using code (Gent 4). The Monte Carlo method is considered one of the most widespread and accurate methods of modeling radiometric processes and has become the most used since the advancement of modern technologies in the field of computer systems.

\section{References}

1. Giusti, L. (2009). A review of waste management practices and their impact on human health. Waste management, 29(8), 2227-2239.

2. Holm, L. E., Hubbard, L., Larsson, C. M., \& Sundell-Bergman, S. (2002). Radiological protection of the environment from the Swedish point of view. Journal of Radiological Protection, 22(3), 235.

3. Carvalho, F. P. (2011). Environmental radioactive impact associated to uranium production. American Journal of Environmental Sciences, 7(6), 547

4. Morton, A., Airoldi, M., \& Phillips, L. D. (2009). Nuclear risk management on stage: a decision analysis perspective on the UK's Committee on Radioactive Waste Management. Risk Analysis: An International Journal, 29(5), 764-779.

5. Bergmans, A., Sundqvist, G., Kos, D., \& Simmons, P. (2015). The participatory turn in radioactive waste management: deliberation and the socialtechnical divide. Journal of Risk Research, 18(3), 347-363.

6. Lee, W. E., Ojovan, M. I., \& Jantzen, C. M. (Eds.). (2013). Radioactive waste management and contaminated site clean-up: Processes, technologies and international experience. Elsevier.

7. Blowers, A., \& Sundqvist, G. (2010). Radioactive waste management-technocratic dominance in an age of participation. Journal of Integrative Environmental Sciences, 7(3), 149-155.

8. Poskas, P., Adomaitis, J. E., Ragaisis, V., Simonis, V., Smaizys, A., Kilda, R., \& Grigaliuniene, D. 
(2012). Progress of radioactive waste management in Lithuania. Progress in Nuclear Energy, 54(1), 1121.

9. McCarthy, G. J. (Ed.). (2012). Scientific Basis for Nuclear Waste Management: Volume 1 Proceedings of the Symposium on "Science Underlying Radioactive Waste Management," Materials Research Society Annual Meeting, Boston, Massachusetts, November 28-December 1, 1978. Springer Science \& Business Media.

10. Khan, S., Syed, A. T., Ahmad, R., Rather, T. A., Ajaz, M., \& Jan, F. A. (2010). Radioactive waste management in a hospital. International journal of health sciences, 4(1), 39 .

11. Kermisch, C. (2016). Specifying the concept of future generations for addressing issues related to high-level radioactive waste. Science and engineering ethics, 22(6), 1797-1811.

12. Kermisch, C., \& Taebi, B. (2017). Sustainability, ethics and nuclear energy: Escaping thdichotomy. Sustainability, 9(3), 446.

13. Meacham, P. G., Anderson, D. R., Bonano, E. J., \& Marietta, M. G. (2011). Sandia National Laboratories performance assessment methodology for long-term environmental programs: The history of nuclear waste management. SAND2011-8270, Sandia National Laboratories, Albuquerque, NM.

14. Al-Ansari, N. A., Knutsson, S., \& Pusch, R. (2014). Environmental Implications of Depleted Uranium in Iraq and Principles of Isolating It. Waste Management, 367-376.

15. Carvalho, F. P. (2011). Environmental radioactive impact associated to uranium production. American Journal of Environmental Sciences, 7(6), 547.

16. Blackman Jr, W. C. (2016). Basic hazardous waste management. CRC press.

17. Aja, O. C., Al-Kayiem, H. H., Zewge, M. G., \& Joo, M. S. (2016). Overview of hazardous waste management status in Malaysia. Management of Hazardous Wastes, (October).

18. Weiner, R., Matthews, R., \& Vesilind, P. A. (2003). Environmental engineering. ButterworthHeinemann.

19. Birpınar, M. E., Bilgili, M. S., \& Erdoğan, T. (2009). Medical waste management in Turkey: A case study of Istanbul. Waste management, 29(1), 445-448.

20. Hamdaoui, S., Mahdaoui, M., Allouhi, A., El Alaiji, R., Kousksou, T., \& El Bouardi, A. (2018). Energy demand and environmental impact of various construction scenarios of an office building in Morocco. Journal of Cleaner Production, 188, 113124.

21. International Atomic Energy Agency, "Implications of Partitioning and Transmutation in Radioactive Waste Management”, IAEA Technical Report 435 (2004).
22. JOINT RESEARCH CENTRE, EUROPEAN ACADEMIES' SCIENCE ADVISORY COUNCIL, Management of Spent Nuclear Fuel and its Waste, Publications Office of the European Union, Luxembourg (2014).

23. WORLD NUCLEAR ASSOCIATION, Processing of Used Nuclear Fuel (May 2012),

24. JOINT RESEARCH CENTRE, EUROPEAN ACADEMIES' SCIENCE ADVISORY COUNCIL, Management of Spent Nuclear Fuel and its Waste, Publications Office of the European Union, Luxembourg (2014). 